\title{
Taxonomic Abundance at Panxian Dadong, a Middle Pleistocene Cave in South China
}

\author{
$\Delta \cdot \Delta \cdot \Delta$ \\ DEBORAH BEKKEN, LYNNE A. SCHEPARTZ, \\ SARI MILLER-ANTONIO, HOU YAMEI, AND HUANG WEIWEN
}

FAUNAL STUDIES HAVE BEEN AN IMPORTANT COMPONENT OF PALEOLITHIC research in China, where pioneering work focused on understanding the taxonomic richness and diversity of Quaternary localities across the country (e.g., Pei 1934a, b, 1957; Qi 1989; Young 1939; Zhou 1964). Paleontological studies at early archaeological sites provide a rich understanding of taxonomic diversity as well as paleoenvironmental parameters and the potential interactions of early humans with mammalian species (Han and $\mathrm{Xu}$ 1985, 1989; Huang and Fang 1991; Qi 1989, 1991; Xu 1984; Xue and Zhang 1991). Faunal information has been used to infer the quality of resources potentially available for hominids to exploit (e.g., Jin et al. 2000), but the role of hominids as agents of accumulation for faunal remains has not generally been the focus of these studies. Rather, lithic artifacts and the presence of anthropogenic materials such as charcoal have been the primary data for reconstructions of hominid behavioral complexity (Jia 1980; Jia and Huang 1985). The extent to which early humans relied on available plant and animal resources, and the methods they used to collect them, have been surmised from the nature of the stone toolkit and the temporal context. This has tended to obscure the complexity of sites and possible use of localities by both hominids and carnivores (Keates 1997, 2001a,b). The exception to this general statement is the site of Zhoukoudian, in which early work by Pei (1934a, 1938) and Weidenreich (1934) demonstrates an analytical framework that recognized the role of other taxa, such as the large carnivores, as an important component in the accumulation of the site contents. Although reconstructions of early hominid subsistence at Zhoukoudian Locality 1 ascribed a strong role to hominids and argued that they were cave dwellers who hunted, used fire, and collected plant resources (Black 1931; Black et al. 1933; Breuil 1939), later research has cast doubt on this picture. Subsequent research has demonstrated a strong role for

Deborah Bekken is with The Field Museum of Natural History in Chicago; Lynne A. Schepartz is with the Department of Anthropology at the University of Cincinnati, Ohio; Sari Miller-Antonio is with the Department of Anthropology/Geography of California State University, Stanislaus; Hou Yamei and Huang Weiwen are with the Chinese Academy of Sciences, Institute of Vertebrate Paleontology and Paleoanthropology, in Beijing.

Asian Perspectives, Vol. 43, No. 2 (C) 2004 by the University of Hawai'i Press. 
other taxa, such as the large carnivores, in the accumulation of the cave deposited fauna (Binford and Ho 1985; Binford and Stone 1986; Boaz et al. 2000).

Faunal assemblages may also be used to address issues of taxonomic abundance, site formation processes, and agents of accumulation (Lyman 1994; Stiner 1994). In addition, the relative abundance of fauna, in contrast to other artifact categories at most Chinese sites, renders faunal assemblages attractive data sets from which to draw inferences about sites and their surrounding environment. Analysis of faunal material from Chinese Paleolithic sites does not routinely include quantitative information. Paleontological, biostratigraphic, and biogeographic analyses are often very thorough (Dong et al. 2000; Han and Xu 1985, 1989; Pei 1934a, b, 1957; Qi 1989, 1991; Xue and Zhang 1991; Young 1939), though discussions of taxonomic abundance or distribution are not as common (but see Jia 1980:39). Measures of taxonomic abundance and taphonomic data have not been systematically collected until recently (Bakken 1994; Boaz et al. 2000; Dong 1996; Jin et al. 2000). The situation is different for Southeast Asia, where there is a stronger tradition of quantification (see, for example, Vu The Long et al. 1996).

The focus of this paper is to investigate the faunal assemblage from Panxian Dadong to further understand species abundance, temporal variability in taxonomic representation, and the role of several potential agents in the accumulation of the faunal assemblage. Paleontological data from other regional hominid sites are included to illustrate the range of faunal communities that characterize Middle Pleistocene southern Chinese localities.

\section{BACKGROUND}

\section{Site Characteristics}

Dadong Cave is located in western Guizhou Province in southern China at an elevation of $1630 \mathrm{~m}$ above sea level $\left(25^{\circ} 37^{\prime} 38^{\prime \prime} \mathrm{N}, 104^{\circ} 44^{\prime} \mathrm{E}\right)$ (Fig. 1). It is a large karst cave situated in a small valley on the mountainous Guizhou Plateau. Due to tectonic uplift in the area, the present entrance lies $32.4 \mathrm{~m}$ above the valley floor. During the Middle Pleistocene, however, the cave entrance would have been closer to the valley floor, and Dadong's spacious interior would have provided excellent shelter to a variety of taxa. The juxtaposition of upland valleys and mountain slopes offered a range of niches within the catchment area. Access to water was another key feature of the Dadong area during the Middle Pleistocene. Geological reconstructions indicate that the valley was drained by three small rivers that flowed below Dadong Mountain. Downcutting during the Early Pleistocene formed the initial valley structure, characterized by attendant streams that periodically developed subsurface channels or drained into subsurface channels (Xiong and Liu 1997; Xiong et al. 1997). Such easy access to permanent water sources would have attracted a diverse fauna, including hominids.

Dadong was initially investigated in $1990-1993$ by a multi-institutional Chinese team (Huang et al. 1997) (Fig. 2). These early investigations clarified the extent of the deposits (as much as $19 \mathrm{~m}$ in some areas) and the range of mammalian taxa in brecciated pockets and areas of stratified sediments (Liu and Si 1997; Pan and Yuan 1997; Zhang et al. 1997). The present team has conducted four seasons of excavations in which $36 \mathrm{~m}^{2}$ were opened to varying depths, with a maximum depth of almost four meters (see inset, Fig. 2). Uranium-series (U-series) (Shen 


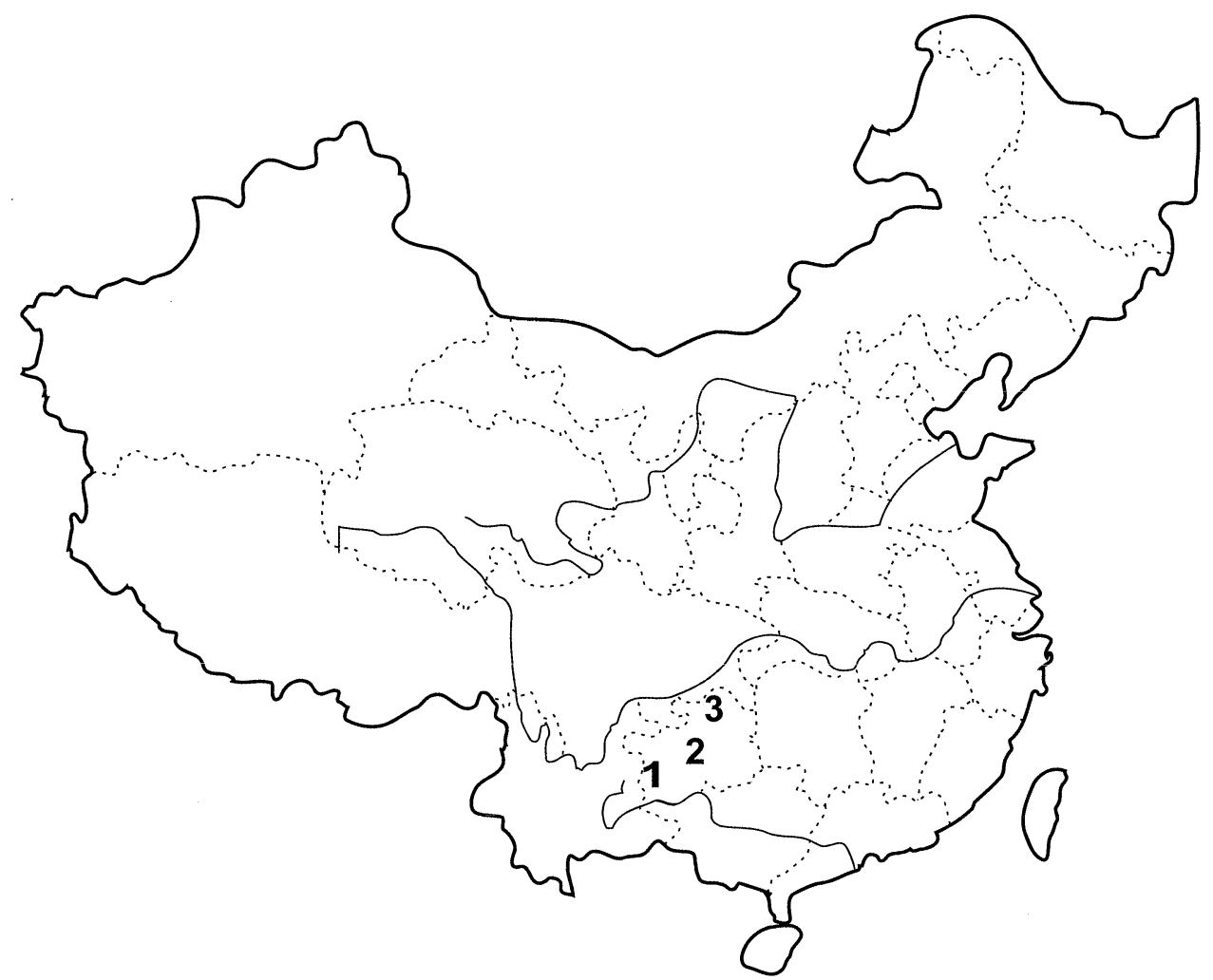

Fig. 1. Map of China with Panxian Dadong and other sites mentioned in the text. 1. Panxian Dadong; 2. Guanyindong; 3. Tongzi.

et al. 1997) and electron spin resonance (ESR) (Rink et al. 2003) estimates of the age of the deposits considered here range from approximately 130 to 260 kya. The excavations yielded a large sample of faunal elements $(\mathrm{n}=7046)$, lithic artifacts, and five human teeth.

Dadong is broadly similar to many other cave contexts in China in that it is a relatively low-density site in terms of both fauna and stone artifacts. The highdensity concentrations of bone that are distinctive features of many European and Near Eastern sites are generally absent in East Asia. Possible exceptions include Zhoukoudian Locality 1 and Hexian (Bakken 1994; Dong et al. 2000). Bone preservation is also comparable to other Chinese cave-derived samples and is characterized by moderate amounts of surface damage and few elements with extensive loss of bone matrix (Bakken 1994, 1997). In addition, the Dadong fauna shows low levels of modification by rodents, carnivores, or hominids (see below and also Schepartz et al. 2003).

\section{Faunal Diversity and General Environmental Indicators}

The fauna from Dadong is a varied assemblage of taxa that are, in general, common components of the Ailuropoda-Stegodon faunas of southern China during the 


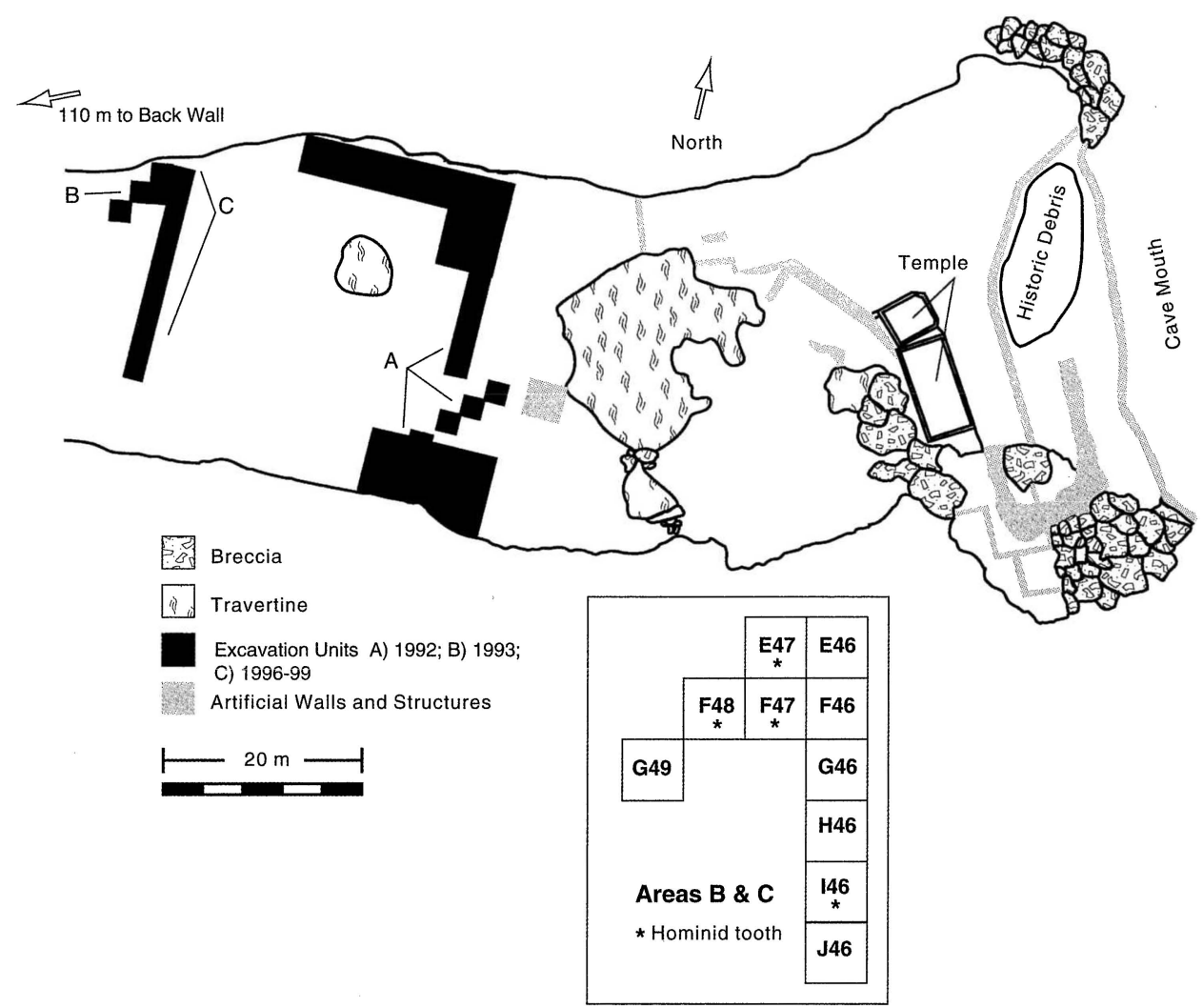

Fig. 2. Panxian Dadong main chamber excavations. The excavation area designated Area $\mathrm{C}$ consists of a long trench that was cleared of approximately one meter of disturbed sediments. Controlled excavations then followed in the north portion of the trench, as shown in the insert.

Middle Pleistocene (Table 1). Although the term 'Ailuropoda-Stegodon fauna' is often used to describe quite distinct faunas from both the Lower and Middle Pleistocene, the Middle Pleistocene component of that fauna is what is being referenced here, and our usage of the term follows that of Han and Xu (1985), Qi (1991), and Xue and Zhang (1991). At Dadong, large-bodied taxa include hominids, proboscideans such as Stegodon orientalis, large carnivores (tiger, bear, and hyena), and a variety of ungulates (cervids, bovids, rhinoceroses, pigs, and giant tapirs). Smaller-bodied taxa include insectivores and rodents (white-toothed shrew, porcupine, and bamboo rat), primates such as the macaque, smaller ungulates (muntjak, musk deer), and small carnivores (weasels and tiger cat).

The environmental tolerances of these species suggest a mixed woodland environment that contains at least two or three kinds of habitat. Areas of bamboo forest are implied not only by the presence of the panda, Ailuropoda, but also by Rhizomys, the bamboo rat. The occurrence of musk deer, barking deer, giant tapir, and rhinoceros suggest mixed woodland with abundant browse. Access to more open, rocky areas with abundant grasses is suggested by the presence of the goral (Naemorhedus goral), and by other small grazers such as the serow (Capricornis sumatraensis). The biogeography of the taxa at Dadong implies a lush and varied 
Table i. Taxonomic Representation for Mammals at Panxian Dadong, GuANYindong, AND TONGzi

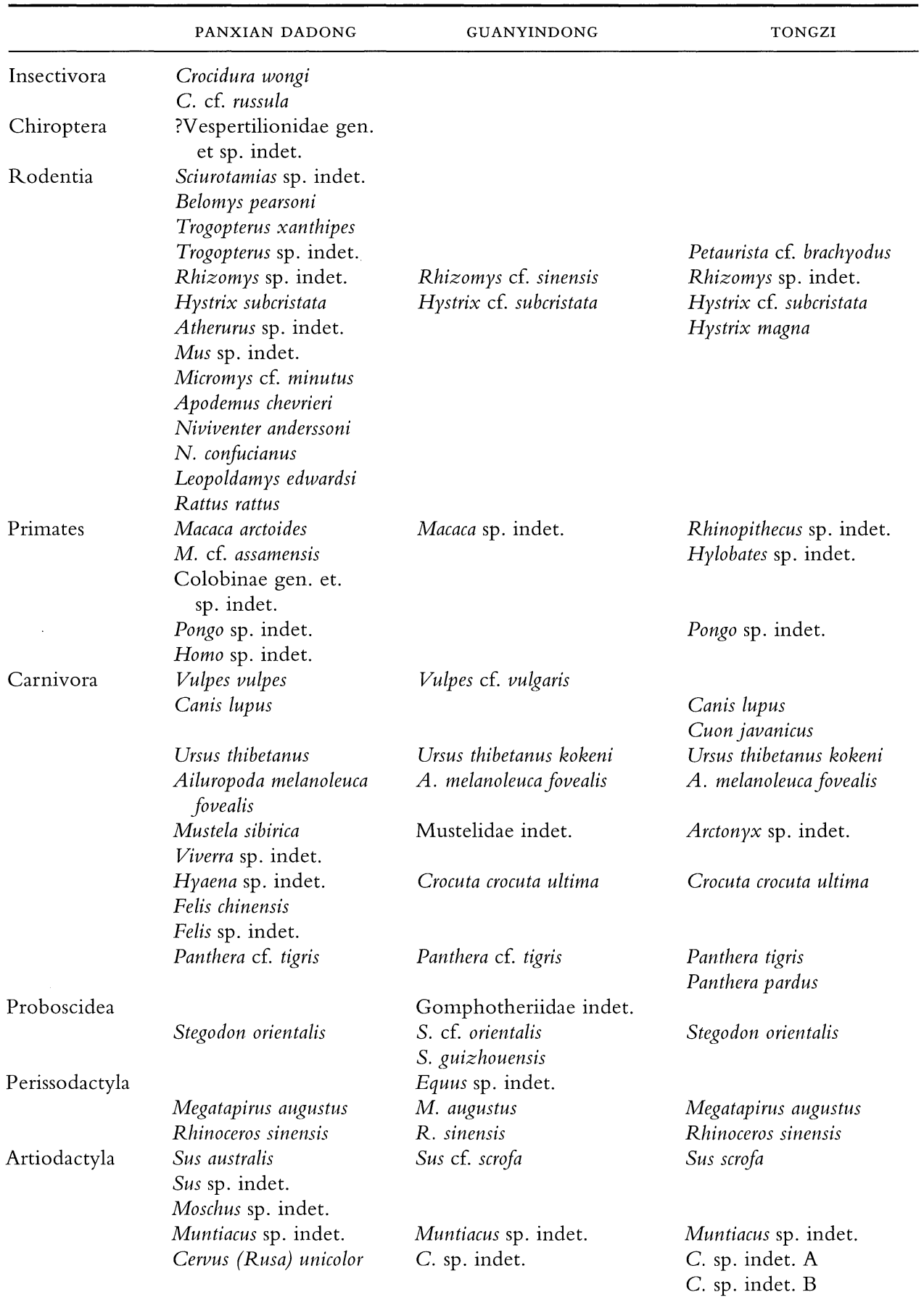


TABLe I (Continued)

\begin{tabular}{lll}
\hline PANXIAN DAdONG & \multicolumn{1}{c}{ GUANYINDONG } & \multicolumn{1}{c}{ TONGZI } \\
\hline Pseudaxis sp. indet. & C. cf. Pseudaxis sp. indet. & \\
Capricornis sumatraensis & Capricornis sumatraensis & \\
Naemorhedus goral & & \\
Megalovis guangxiensis & & \\
Bubalus sp. indet. & Bubalus sp. indet. & \\
Bison sp. indet. & Bibos sp. indet. & Bovidae gen. et sp. indet. \\
\hline
\end{tabular}

Sources: modified, respectively, from Liu and Si 1997; Pan and Yuan 1997; Zhang et al. 1997; Li and Wen 1986; and Han and Xu 1985; Qiu 1985.

environment with plentiful low vegetation cover and easy access to open water or river edge.

A comparison of species representation from other Middle Pleistocene archaeological sites in Guizhou Province helps to place the Dadong fauna within a regional framework. Two roughly contemporaneous sites, Guanyindong, a karst cave located in northwestern Guizhou, and Tongzi, a cave located in northern Guizhou, are very similar to Dadong in certain respects (Fig. 1). Guanyindong is a small cave in which excavations recovered a collection of stone artifacts that $\mathrm{Li}$ and Wen (1986) attribute to the Lower Paleolithic. U-series dates of 100-190 kya place the site in the late Middle Pleistocene (Shen 1993). Li and Wen (1986) conclude that the environmental reconstruction that best fits the assemblage is one of mixed woodland with access to wetland and lacustrine environments. Certain taxa such as panda (Ailuropoda) and bamboo rat (Rhizomys) imply the presence of bamboo forest as well (Table 1). Guanyindong shares many taxa with Dadong, but notable exceptions include Equus (horse) and Bibos (gaur). Their presence suggests access to open grassy areas that could support large grazers. Additional taxa found at Guanyindong but not at Dadong include the elephant-like gomphotheres. This group persisted only until the Middle Pleistocene, and their occurrence at Guanyindong indicates that this fauna should be older than that found at Dadong (Han and $\mathrm{Xu}$ 1985, 1989). Regarding the carnivores, however, Guanyindong also includes the hyena genus Crocuta, rather than Hyena, which is present at Dadong. Crocuta is generally associated with Late Pleistocene deposits, while Hyena is associated with Early and Middle Pleistocene deposits (Xue and Zhang 1991). The presence of Crocuta at Guanyindong indicates that the deposits should be somewhat younger than Dadong. Given the combination of the available radiometric dates and the taxonomic community it seems probable that Guanyindong spans the time period represented at Dadong.

The site of Tongzi has yielded six hominid teeth, a small assemblage of artifacts, burned bone, and mammalian taxa (Olsen and Miller-Antonio 1992; Qiu 1985). Though the site is stratified (seven layers were identified during excavation), all the hominid specimens, artifacts, and fauna derive from the fourth layer. U-series dates of 172-192 kya and 214 kya are in agreement with the biostratigraphic material and place the site in the late Middle Pleistocene (Wang 1989). The Tongzi fauna displays two noteworthy differences from the Dadong faunal 
assemblage that suggest the Tongzi area was perhaps more heavily forested (Table 1). The presence of the gibbon (Hylobates) is interesting in that it implies closedcanopy forest and tropical conditions in the vicinity of the cave. Evidence of the giant flying squirrel (Petaurista) also suggests extensive forest with trees of significant height as opposed to shorter scrub growth. Large-bodied genera such as Stegodon, Rhinoceros, and the giant tapir Megatapirus are broadly indicative of the prevailing subtropical to tropical regime in South China during the later stages of the Middle Pleistocene that characterizes Dadong, Guanyindong, and Tongzi.

\section{SAMPLE CHARACTERISTICS AND METHODOLOGY}

The Dadong faunal sample analyzed here includes data from three seasons of excavations in the cleared north-south trench located in the central chamber (see inset, Fig. 2). The data from the 1996 field season are excluded as they provide very little material identifiable to taxon and, interestingly, differ taphonomically from the rest of the assemblage. The 1996 excavations involved the two squares closest to the north wall of the cave, and the recovered bone sample shows more fragmentation and surface damage than elements recovered during subsequent seasons.

The faunal data are recovered and studied using the following procedures. Specimens over $2.5 \mathrm{~cm}$ are piece-plotted, and other material is recovered from screening or sorting of the intractable sediments. All specimens are identified, measured, and analyzed for surface characteristics and damage while the team is in the field. A selection of specimens was further identified at The Field Museum using an extensive comparative collection. Species identifications are made primarily on the dentition and on distinctive features of the postcranial skeleton. A total of 2001 piece-plotted bone and tooth specimens were recovered. The additional material from screening and sorting includes 4522 elements, bringing the total sample to 6523 elements. Approximately 19 percent $(n=1256)$ were identified to taxonomic group; of these, more than 95 percent were from the pieceplotted material.

In the following analysis, several species that share general size and behavioral characteristics have been grouped together in larger categories to facilitate interpretation of the data. 'Small bovid' includes animals roughly the size of a serow (Capricornis) and smaller ( $\leq 150 \mathrm{~kg}$ ), while 'large bovid' includes animals the size of a water buffalo (Bubalus) and larger ( $\geq 400 \mathrm{~kg}$ ). 'Small cervid' includes animals the size of the muntjak or barking deer (Muntiacus) and smaller $(\leq 20 \mathrm{~kg}$ ), while 'large cervid' includes animals the size of sika deer (Pseudaxis) and larger ( $\geq 50 \mathrm{~kg})$. The carnivores are also grouped according to size, with 'small carnivore' including animals the size of a fox (Vulpes) and smaller $(\leq 22 \mathrm{~kg})$, and 'large carnivore' including animals the size of a wolf (Canis) and larger $(\geq 25 \mathrm{~kg})$. The panda (Ailuropoda) is included in 'large carnivore' because its fragmentary elements are very difficult to differentiate from those of bears (apart from the dentition). The porcupine (Hystrix) is easy to identify and is potentially important as an agent of bone modification and accumulation. It is listed separately, while all other rodents and insectivores are listed under 'Other Insectivora and Rodentia.' For the Primates, the genus Homo is listed singly, and all other species are recorded under 'Other Primates.' 


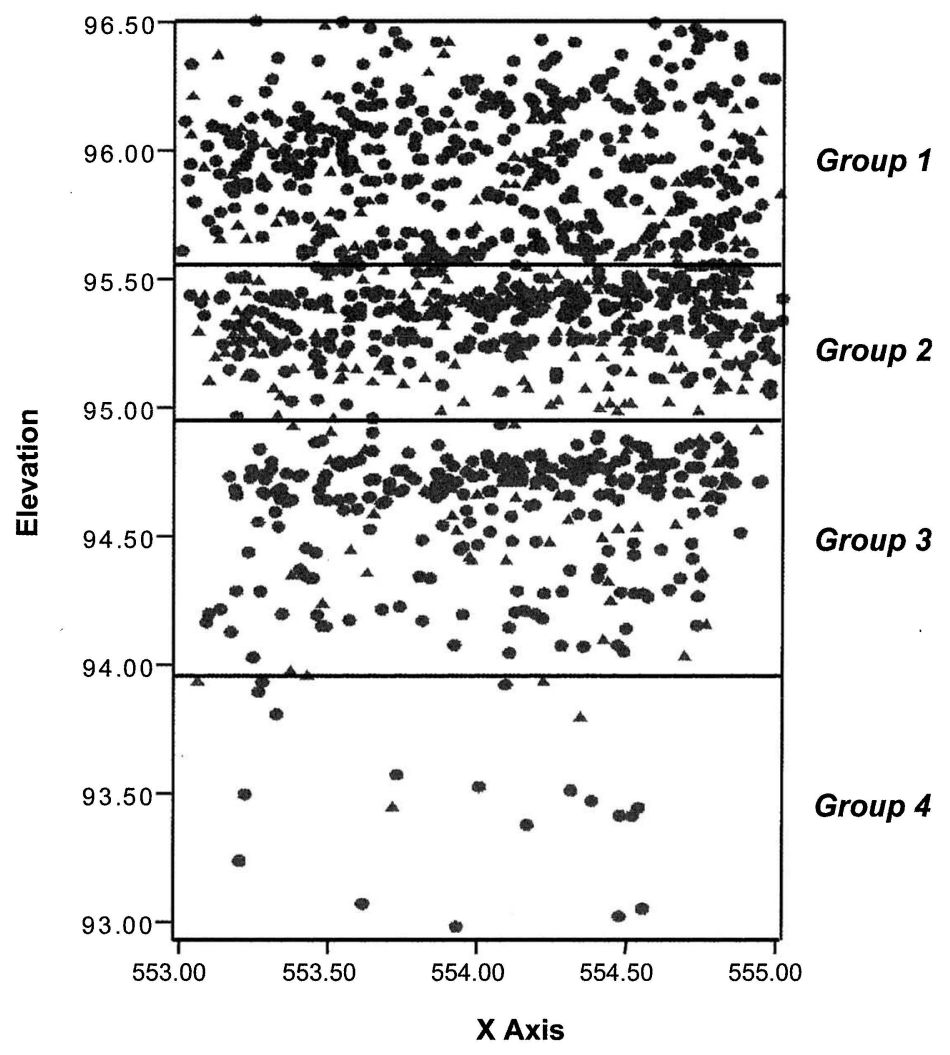

\section{Tooth Bone}

Fig. 3. Schematic profile view of excavated deposits with elevations relative to datum for Groups $1-4$.

\section{Temporal Groupings}

As the Dadong assemblage was formed over a considerable period of time and during periods of climatic change (Wang Wei et al. this volume), it is useful to create some subdivisions of the data set. While distinct occupation "floors" or features are not apparent at Dadong, the deposits can be divided into broad temporal groupings (Fig. 3). In a previous study that addressed questions of site formation, the faunal sample was divided using temporal differences in the concentrations of the piece-plotted material (Schepartz et al. 2003). In this study, we make the divisions using our now available data on the age of the deposits (Rink et al. 2003) and the geomorphology (Wang Wei et al. this volume).

Temporal divisions, labeled Group 1 through Group 4, are designated in reference to their stratigraphic position in relation to radiometric dating samples (Table 2). Group 1 ranges in depth from 96.5 to $95.6 \mathrm{~m}$ (elevations are given in terms of their locations below datum, which is set at $100 \mathrm{~m}$; thus 96.5 is $3.5 \mathrm{~m}$ below datum), Group 2 ranges from 95.5 to $95.0 \mathrm{~m}$, Group 3 is from 94.9 to $94.0 \mathrm{~m}$, and Group 4 ranges from 93.9 to $92.9 \mathrm{~m}$ (Fig. 3 and Miller-Antonio et al. this volume). 
Table 2. Elevation and ESR Dating Correlations for Temporal Groups Elevations given as METERS BelOW DATUM, SET AT IOO $\mathrm{m}$

\begin{tabular}{|c|c|c|c|c|c|c|c|}
\hline & $\begin{array}{l}\text { ELEVATION } \\
\text { RANGE }\end{array}$ & MATERIAL DATED & SAMPLE \# & $\begin{array}{l}\text { ELEVATION OF SAMPLE } \\
\text { (m BELOW DATUM) }\end{array}$ & $\begin{array}{c}\text { AGE (kya) } \\
\text { EARLY UPTAKE }\end{array}$ & $\begin{array}{c}\text { AGE (kya) } \\
\text { LATE UPTAKE }\end{array}$ & \\
\hline \multirow[t]{3}{*}{ Group 1} & \multirow[t]{3}{*}{$96.5-95.6 \mathrm{~m}$} & Rhinoceros tooth & PD3A & 95.188 & $124(14)$ & $166(21)$ & \\
\hline & & Bovid tooth & PD4C & 95.473 & $118(14)$ & $131(18)$ & \\
\hline & & Bovid tooth & PD6A & 95.409 & 159 (19) & $181(25)$ & \\
\hline \multirow[t]{3}{*}{ Group 2} & \multirow[t]{3}{*}{$95.5-95.0 \mathrm{~m}$} & Rhinoceros tooth & PD8A & 95.111 & $144(23)$ & $154(26)$ & \\
\hline & & Rhinoceros tooth & PD10A & 94.974 & $142(23)$ & $149(23)$ & \\
\hline & & & & & $137\{16\}$ & $156\{18\}$ & Mean \\
\hline \multirow[t]{2}{*}{ Group 3} & \multirow[t]{2}{*}{$94.9-94.0 \mathrm{~m}$} & Rhinoceros tooth & PD17A & 94.156 & $247(29)$ & $301(42)$ & \\
\hline & & Rhinoceros tooth & PD18A & 94.035 & $195(21)$ & $250(32)$ & \\
\hline \multirow[t]{3}{*}{ Group 4} & \multirow[t]{3}{*}{$93.9-92.9 \mathrm{~m}$} & Rhinoceros tooth & PD16A & 93.939 & $199(26)$ & 228 (17) & \\
\hline & & Rhinoceros tooth & PD15A & 93.798 & $214(24)$ & $268(36)$ & \\
\hline & & & & & $214\{24\}$ & $262\{31\}$ & Mean \\
\hline
\end{tabular}

ESR dates from Rink et al. (2003). 
Group 1 is most recent in age (younger than 137-156 kya), and is situated above Group 2, which is associated with a cluster of ESR (electron spin resonance) dating samples collected from five mammalian teeth between 95.5 and $95.0 \mathrm{~m}$ in depth (approximately $1.8 \mathrm{~m}$ below the present surface). Mean ages for these samples are between 137 kya (Early Uptake Model) to 156 kya (Late Uptake Model) (Rink et al. 2003). The Group 3 sample encompasses those sediments with four ESR mammalian tooth samples collected between 94.2 and $94.0 \mathrm{~m}$ in depth (roughly $5.8-6.0 \mathrm{~m}$ below datum or $3.0 \mathrm{~m}$ below the present surface). Recovered mean ages from these dating samples range between 214 kya (Early Uptake Model) and 262 kya (Late Uptake Model) (Rink et al. 2003). The fourth and oldest grouping comes from sediments below these deeper-dating samples.

\section{Measure of Taxonomic Abundance}

Several methods for measuring taxonomic abundance have been devised for archaeological site samples. Of these, one of the most robust measurements is the Number of Identified Specimens (NISP). NISP counts are straightforward in that they are the sum of individual identified elements or fragments for a given taxon. NISP counts are perhaps least affected by issues of data aggregation and interdependence of individual specimens (Grayson 1984; Klein and Cruz-Uribe 1984; Lyman 1994). They require fewer assumptions regarding the data set than other measures of abundance such as the Minimum Number of Individuals (MNI) or the Minimum Number of Elements (MNE). Limitations to the use of NISP are discussed at length in Grayson (1984).

\section{RESULTS}

\section{Number of Identified Specimens}

Values for numbers of identified specimens are given in Table 3. NISP counts incorporate as many determinable elements or element fragments as are available for a particular taxon. Isolated teeth are included in Table 3 along with bone specimens. Of the 1256 specimens included in Table 3, the highest percentage of elements come from Group 3 (46\%), while Group 2 accounts for 35 percent of the sample. The youngest sediments, Group 1, contain 18 percent of sampled elements. Faunal elements and lithic artifacts occur in the oldest sediments represented by Group 4; however, Group 4 elements account for only 1 percent of the sample in Table 3. As excavations have proceeded to this depth in only two squares (G46, F46, Fig. 2 inset), this level is not adequately sampled in comparison to Groups 1 through 3.

Large-bodied taxa dominate the sample, but there is also a good representation of insectivores and rodents. Based on NISPs, the rhinoceros is the most abundant taxon in Groups 1 through 3 (Table 3). Elements of the rhinoceros account for 27 percent of the sample; slightly more than one-quarter of all elements are from this one taxon. Other abundant animals include the large bovids (17\%) and Stegodon (13\%). Large and small carnivores account for 5 percent of the sample, while the giant tapir (Megatapirus) represents 3 percent of the sample. A small sample of birds $(1 \%)$ is also present at the site including cranes (Gruidae) and eagles (Aquila 
Table 3. Numbers of Identified Specimens (NISP) fOR Dadong TAXA LISTED IN DESCENDING ORDER ACCORDING TO NISP COUNTS

\begin{tabular}{lrrrrr}
\hline & $\begin{array}{c}\text { GROUP I } \\
\text { NISP }\end{array}$ & $\begin{array}{c}\text { GROUP 2 } \\
\text { NISP }\end{array}$ & $\begin{array}{c}\text { GROUP } 3 \\
\text { NISP }\end{array}$ & $\begin{array}{c}\text { GROUP 4 } \\
\text { NISP }\end{array}$ & $\begin{array}{c}\text { ALL GROUPS } \\
\text { NISP }\end{array}$ \\
\hline Rhinoceros & 52 & 113 & 168 & 2 & $\mathbf{3 3 5}$ \\
Large Bovids & 43 & 108 & 57 & 0 & $\mathbf{2 0 8}$ \\
Stegodon & 35 & 57 & 73 & 3 & $\mathbf{1 6 8}$ \\
Small Bovids & 15 & 29 & 81 & 3 & $\mathbf{1 2 8}$ \\
Small Cervids & 7 & 20 & 86 & 0 & $\mathbf{1 1 3}$ \\
Large Cervids & 15 & 40 & 42 & 1 & $\mathbf{9 8}$ \\
Other Insectivora and Rodentia & 34 & 28 & 5 & 2 & $\mathbf{6 9}$ \\
Large Carnivores & 6 & 15 & 19 & 0 & $\mathbf{4 0}$ \\
Megatapirus & 5 & 15 & 12 & 1 & $\mathbf{3 3}$ \\
Aves & 0 & 3 & 14 & 0 & $\mathbf{1 7}$ \\
Small Carnivores & 8 & 6 & 4 & 0 & $\mathbf{1 8}$ \\
Hystrix & 4 & 6 & 3 & 0 & $\mathbf{1 3}$ \\
Sus & 2 & 1 & 9 & 0 & $\mathbf{1 2}$ \\
Homo & 1 & 0 & 1 & 0 & $\mathbf{2}$ \\
Other primates & 0 & 1 & 0 & 0 & $\mathbf{1}$ \\
Chiroptera & 1 & 0 & 0 & 0 & $\mathbf{1}$ \\
All Taxa & $\mathbf{2 2 8}$ & $\mathbf{4 4 2}$ & $\mathbf{5 7 4}$ & $\mathbf{1 2}$ & $\mathbf{1 2 5 6}$ \\
\hline
\end{tabular}

sp.). Rare taxa together account for 5 percent of the sample and they include bats, primates, hominids, pigs (Sus), and porcupines (Hystrix).

The majority of rhinoceros specimens derive from Group 3, with an additional large sample in Group 2. Given the NISP numbers for each group, it can be seen that rhinoceroses comprise between 23 and 29 percent of the sample in Groups 1 through 3. Other large-bodied animals are distributed in a similar fashion. For example, the Stegodon sample ranges from 13 to 15 percent in Groups 1 through 3.

In the youngest sediments (Group 1), rhinoceroses predominate, followed closely by large bovids, Stegodon, and rodents and insectivores. Group 1 has the largest sample of insectivores and rodents at Dadong as well as the largest number of small carnivore elements. The sample from Group 2 also contains a large number of rhinoceros elements, followed by large bovids, Stegodon, and large cervids. A smaller sample of insectivore and rodent material is also found, accounting for 6 percent of the sample. More elements of porcupine (Hystrix) are found in Group 2 than in other levels, as is the case for the giant tapir Megatapirus. The Group 3 sample also has a predominance of rhinoceros material, followed by small cervids and small bovids. These two taxonomic groups are represented by greater numbers of elements in Group 3 than in other levels, and this is also the case for Stegodon, large cervids, and large carnivores. The pig (Sus) is not a common taxon within the assemblage, but the greatest number of pig elements occurs in Group 3. This is the case for the birds as well.

\section{Temporal Perspectives}

One way to think about the temporal distribution of taxa at Dadong is to compare total abundance of grouped taxa among the groups. As presented in Table 3, 
Table 4. NisP Values Standardized by Volume for Temporal Groups at Dadong

\begin{tabular}{lclll}
\hline & GROUP I & GROUP 2 & GROUP 3 & GROUP 4 \\
\hline Volume $\left(\mathrm{m}^{3}\right)$ & 14.28 & 13.528 & 19.048 & 7.732 \\
Standardized NISP & 15.97 & 32.67 & 30.13 & 1.55 \\
\hline
\end{tabular}

the Dadong sample appears to display two patterns of overall animal abundance. Groups 2 and 3 seem to be richer in numbers of specimens, and Group 1 is less dense with fewer individuals represented. Total NISP values are highest in Group 3 ( $n=574$, representing almost 46 percent of the identified taxonomic group sample). Group 2 is similar, with 35 percent of elements identified to taxon. Group 1 has roughly half the specimens of Group 2, and it represents 18 percent of the total sample. However, to fully understand the temporal patterning of taxonomic abundance at Dadong, the total volume of sediment for each of the groups needs to be factored into any comparisons. The groups vary greatly in their volumes (Table 4). If the group NISPs are standardized by dividing the total counts by the group volume, it is clear that Group 2 and Group 3 contain more estimated numbers of individuals per unit volume and that the density of faunal remains at Dadong is highest within these two time periods.

Although the preceding discussion of taxonomic abundance at Dadong has emphasized the ways in which the groups differ, one of the striking characteristics of the Dadong fauna is the consistency of taxonomic representation over time. There is no evidence for significant changes in species representation that correlates with the known climatic changes that occurred during the formation of the assemblage. Most of the Dadong species are highly adaptable forms with fairly broad environmental tolerance ranges.

\section{Representation of Elements and Fragmentation}

The rhinoceros is the most well-represented taxon at Dadong, and it is a ubiquitous member of southern Chinese faunas during the Pleistocene. While present in large numbers across Groups 1 through 3 (Table 3), the distribution of elements does vary. Isolated teeth predominate in the younger levels, while the greatest diversity of elements is to be found in Group 3 and is comprised of portions of the forefoot and hindfoot, as well as appendicular elements such as the humerus, tibia, femur, and radius (Table 5).

As mentioned above, the Dadong sample is highly fragmented. Common elements include small, dense components such as teeth, carpals and tarsals, short metapodials, and sesamoids; this can be seen in the element representation for the rhinoceros sample (Table 5) where these dense elements and isolated teeth predominate. Large bovids and cervids, large carnivores and giant tapir fit this pattern, as do smaller-bodied taxa such as the suids, small bovids, small cervids, the porcupine, and the small carnivores. Long or delicate axial or appendicular elements are not common elements in the sample. Whether through profile compaction or the effects of other taphonomic processes that break bone, the missing elements are becoming either too fragmentary to identify, or they are no longer present in the sample. 
Table 5. Element Representation by NiSP for Rhinoceroses at PanXian Dadong

\begin{tabular}{lrrrrr}
\hline & GROUP I & GROUP 2 & GROUP 3 & GROUP 4 & totals \\
\hline Isolated Teeth & 49 & 99 & 69 & 0 & $\mathbf{2 1 7}$ \\
Maxilla & 0 & 0 & 1 & 0 & $\mathbf{1}$ \\
Mandible & 0 & 0 & 2 & 0 & $\mathbf{2}$ \\
Cranium & 0 & 0 & 1 & 0 & $\mathbf{1}$ \\
Scapula & 0 & 0 & 1 & 0 & $\mathbf{1}$ \\
Humerus & 0 & 0 & 4 & 0 & $\mathbf{4}$ \\
Ulna & 0 & 0 & 0 & 0 & $\mathbf{0}$ \\
Radius & 0 & 1 & 3 & 0 & $\mathbf{4}$ \\
Patella & 0 & 1 & 0 & 0 & $\mathbf{1}$ \\
Femur & 1 & 0 & 3 & 0 & $\mathbf{4}$ \\
Tibia & 2 & 0 & 3 & 0 & $\mathbf{5}$ \\
Carpal/Tarsal & 0 & 7 & 23 & 0 & $\mathbf{3 0}$ \\
Metapodial & 0 & 3 & 17 & 1 & $\mathbf{2 1}$ \\
Phalanges & 0 & 2 & 41 & 1 & $\mathbf{4 4}$ \\
& $\mathbf{5 2}$ & $\mathbf{1 1 3}$ & $\mathbf{1 6 8}$ & $\mathbf{2}$ & $\mathbf{3 3 5}$ \\
\hline
\end{tabular}

Insectivores, rodents, and birds present a slightly different pattern of element representation. These animals are not primarily represented by small and dense bones of the feet or teeth, as are the groups mentioned above. For rodents, characteristic elements include limb elements and incisors (Table 6). The birds are identified primarily through distal or proximal limb fragments.

Additionally, differences in element representation can be seen among the four groups. Table 7 indicates the numbers of cranial as opposed to postcranial elements over all taxa. Interestingly, in Groups 1 and 2, cranial parts predominate, but in Groups 3 and 4 postcranial elements predominate. Conversely, Group 3 has more postcranial elements than cranial elements, and this pattern suggests the addition of more whole animals to the assemblage. It may be that elements in Group 3 have suffered less fragmentation, such that elements of the appendicular skeleton and head parts have survived burial along with the more expected

Table 6. Element Representation by NiSP for Rodents and Insectivores Other than Porcupines

\begin{tabular}{lccccr}
\hline & GROUP I & GROUP 2 & GROUP 3 & GROUP 4 & totals \\
\hline Isolated Incisors & 20 & 18 & 1 & 1 & $\mathbf{4 0}$ \\
Mandible & 2 & 3 & 0 & 0 & $\mathbf{5}$ \\
Humerus, distal & 2 & 1 & 0 & 0 & $\mathbf{3}$ \\
Femur, proximal & 2 & 1 & 1 & 0 & $\mathbf{4}$ \\
Femur, midshaft & 0 & 1 & 1 & 0 & $\mathbf{2}$ \\
Ulna, proximal & 1 & 1 & 0 & 0 & $\mathbf{2}$ \\
Radius, distal & 0 & 0 & 1 & 0 & $\mathbf{1}$ \\
Tibia & 0 & 1 & 0 & 1 & $\mathbf{2}$ \\
Metapodial & 5 & 0 & 0 & 0 & $\mathbf{5}$ \\
Vertebrae & 0 & 2 & 0 & 0 & $\mathbf{2}$ \\
Innominate & 2 & 0 & 1 & 0 & $\mathbf{3}$ \\
& $\mathbf{3 4}$ & $\mathbf{2 8}$ & $\mathbf{5}$ & $\mathbf{2}$ & $\mathbf{6 9}$ \\
\hline
\end{tabular}


Table 7. Cranial and Postcranial Element Representation Broken Down by Axial and Appendicular Portions for Temporal Groups at DADONG

\begin{tabular}{|c|c|c|c|c|c|c|c|c|c|}
\hline GROUP I & & & & & GROUP 2 & & & & \\
\hline \multirow[t]{4}{*}{ Megatapirus } & Cranial & 0 & & & Megatapirus & Cranial & 1 & & \\
\hline & Isolated teeth & 5 & & & & Isolated teeth & 13 & & \\
\hline & Postcranial & 0 & Axial & 0 & & Postcranial & 0 & Axial & 0 \\
\hline & & & Appendicular & 0 & & & & Appendicular & 0 \\
\hline \multirow[t]{4}{*}{ Rhinoceros } & Cranial & 0 & & & Rhinoceros & Cranial & 0 & & \\
\hline & Isolated teeth & 49 & & & & Isolated teeth & 102 & & \\
\hline & Postcranial & 3 & Axial & 0 & & Postcranial & 11 & Axial & 0 \\
\hline & & & Appendicular & 3 & & & & Appendicular & 11 \\
\hline \multirow[t]{4}{*}{ Large bovids and cervids } & Cranial & 1 & & & Large bovids and cervids & Cranial & 1 & & \\
\hline & Isolated teeth & 44 & & & & Isolated teeth & 109 & & \\
\hline & Postcranial & 13 & Axial & 1 & & Postcranial & 38 & Axial & 5 \\
\hline & & & Appendicular & 12 & & & & Appendicular & 33 \\
\hline \multirow[t]{4}{*}{ Stegodon } & Cranial & 0 & & & Stegodon & Cranial & 0 & & \\
\hline & Isolated teeth & 34 & & & & Isolated teeth & 54 & & \\
\hline & Postcranial & 1 & Axial & 0 & & Postcranial & 3 & Axial & 0 \\
\hline & & & Appendicular & 1 & & & & Appendicular & 3 \\
\hline \multirow[t]{4}{*}{ Small bovids and cervids } & Cranial & 1 & & & Small bovids and cervids & Cranial & 4 & & \\
\hline & Isolated teeth & 17 & & & & Isolated teeth & 34 & & \\
\hline & Postcranial & 4 & Axial & 1 & & Postcranial & 11 & Axial & 1 \\
\hline & & & Appendicular & 3 & & & & Appendicular & 10 \\
\hline
\end{tabular}




\begin{tabular}{|c|c|c|c|c|c|c|c|c|c|}
\hline GROUP 3 & & & & & GROUP 4 & & & & \\
\hline \multirow[t]{4}{*}{ Megatapirus } & Cranial & 1 & & & Megatapirus & Cranial & 0 & & \\
\hline & Isolated teeth & 2 & & & & Isolated teeth & 1 & & \\
\hline & Postcranial & 9 & Axial & 0 & & Postcranial & 0 & Axial & 0 \\
\hline & & & Appendicular & 9 & & & & Appendicular & 0 \\
\hline \multirow[t]{4}{*}{ Rhinoceros } & Cranial & 3 & & & Rhinoceros & Cranial & 0 & & \\
\hline & Isolated teeth & 57 & & & & Isolated teeth & 0 & & \\
\hline & Postcranial & 108 & Axial & 1 & & Postcranial & 2 & Axial & 0 \\
\hline & & & Appendicular & 108 & & & & Appendicular & 2 \\
\hline \multirow[t]{4}{*}{ Large bovids and cervids } & Cranial & 9 & & & Large bovids and cervids & Cranial & 0 & & \\
\hline & Isolated teeth & 22 & & & & Isolated teeth & 1 & & \\
\hline & Postcranial & 68 & Axial & 14 & & Postcranial & 0 & Axial & 0 \\
\hline & & & Appendicular & 54 & & & & Appendicular & 0 \\
\hline \multirow[t]{4}{*}{ Stegodon } & Cranial & 2 & & & Stegodon & Cranial & 1 & & \\
\hline & Isolated teeth & 29 & & & & Isolated teeth & 2 & & \\
\hline & Postcranial & 42 & Axial & 10 & & Postcranial & 0 & Axial & 0 \\
\hline & & & Appendicular & 32 & & & & Appendicular & 0 \\
\hline \multirow[t]{4}{*}{ Small bovids and cervids } & Cranial & 25 & & & Small bovids and cervids & Cranial & 0 & & \\
\hline & Isolated teeth & 40 & & & & Isolated teeth & 1 & & \\
\hline & Postcranial & 102 & Axial & 17 & & Postcranial & 2 & Axial & 1 \\
\hline & & & Appendicular & 85 & & & & Appendicular & 1 \\
\hline
\end{tabular}

Cranial portions include all cranial elements including maxillary and mandibular bone with attached teeth, but excluding isolated teeth. Postcranial elements include all elements excluding unidentifiable fragments. Axial elements include the vertebrae, scapula, clavicle, and innominate. Appendicular elements include all elements of the forefoot and hindfoot, as well as the humerus, radius, ulna, femur, tibia, and fibula. 
Table 8. Mean Values for Greatest Length Measurements of Fragments in Millimeters

\begin{tabular}{lccccc}
\hline & GROUP I & GROUP 2 & GROUP 3 & GROUP 3 & ALL GROUPS \\
\hline Mean fragment greatest length & $56.5 \mathrm{~mm}$ & $57.8 \mathrm{~mm}$ & $71.1 \mathrm{~mm}$ & $65.4 \mathrm{~mm}$ & $\mathbf{6 2 . 7} \mathbf{~ m m}$ \\
\hline
\end{tabular}

abundance of the dense bones of the feet and limbs. As the Group 3 fauna is similar in taxonomic representation to the Group 1 and Group 2 fauna, it is entirely possible that the difference between cranial and postcranial part abundance is due to taphonomic factors that have favored bone preservation in the lower levels of the excavation.

\section{Taphonomy}

As illustrated above, the Dadong sample is characterized by differential preservation of elements; aside from isolated teeth and dense, compact foot bones, virtually all elements are fragmentary. This is not to say, however, that fragment size is necessarily small. Average greatest length measurements indicate that individual fragments can be of good size. Among the four groups, greatest length mean values are given in Table 8 . Because fragments are by definition smaller than the unbroken element, fragments of between 55 and $72 \mathrm{~mm}$ mean size broadly reflect an abundance of large animals with correspondingly large skeletal elements.

Fragmentation may result from trampling and profile compaction. Very likely a combination of both factors is at work at Dadong. Trampling may have a stronger effect on the bones of large animals than on those of small animals (Klein and Cruz-Uribe 1984; Marean 1991), but in the Dadong sample, loss of identifiable elements appears to affect the entire sample regardless of size. In addition, the relatively smaller average fragment sizes for Groups 1 and 2 correlate with the cranial to postcranial disparity in those levels (Table 7). Isolated teeth predominate, potentially due to the fragmentation of cranial elements, such that they are not typically found in identifiable form in those groups. Postcranial elements from Groups 1 and 2 are almost exclusively from the distal limb elements of the forefoot and hindfoot.

\section{AGENTS OF ACCUMULATION}

Another way to address factors that can lead to greater or lesser element representation is by looking at bone modification agents. Bone modification reflects the activities of hominids, carnivores, and rodents. The Dadong fauna can in general be characterized as a "lightly used" sample in that the proportion of elements showing evidence of modification is low (Table 9).

\section{Rodents}

Rodent gnawing is the most commonly found form of modification, and it affects slightly less than 5 percent of the Group 3 sample, the level where it is most frequently observed. A number of rodents are present at Dadong (Table 1), includ- 
Table 9. Frequency of Bone Modification by Rodents, Carnivores, AND HOMINIDS BY GROUP

(n/SAMPLE IN PARENTHESES)

\begin{tabular}{lllll}
\hline & GROUP I & GROUP 2 & GROUP 3 & GROUP 4 \\
\hline Rodent damage & $2.24 \%$ & $3.35 \%$ & $4.52 \%$ & $1.71 \%$ \\
& $(34 / 1521)$ & $(90 / 2683)$ & $(97 / 2144)$ & $(3 / 175)$ \\
Carnivore damage & $1.25 \%$ & $1.90 \%$ & $2.33 \%$ & $1.71 \%$ \\
& $(19 / 1521)$ & $(51 / 2683)$ & $(50 / 2144)$ & $(3 / 175)$ \\
Hominid damage & $0.20 \%$ & $0.19 \%$ & $0.42 \%$ & $0.00 \%$ \\
Cuts only & & & & \\
Burning only & $(3 / 1521)$ & $(5 / 2683)$ & $(9 / 2144)$ & $(0 / 175)$ \\
& $5.13 \%$ & $2.12 \%$ & $0.84 \%$ & $1.14 \%$ \\
All forms & $(78 / 1521)$ & $(57 / 2683)$ & $(18 / 2144)$ & $(2 / 175)$ \\
& $5.32 \%$ & $2.31 \%$ & $1.26 \%$ & $1.14 \%$ \\
& $(81 / 1521)$ & $(62 / 2683)$ & $(27 / 2144)$ & $(2 / 175)$ \\
\hline
\end{tabular}

ing the porcupine, the bamboo rat, squirrels, mice, and rats. Although all size classes of rodent gnawing are lumped together in Table 9, the most common form of gnawing damage is caused by porcupines. These large rodents are found across southern China in the Middle Pleistocene (Xue and Zhang 1991), and they are recognized as an important agent of accumulation for bone samples in Southeast Asia (Vu The Long 1996). Porcupines are well known for their bone collecting and gnawing activities (Lyman 1994; Brain 1981). These animals have open-rooted incisors that grow continuously, and grow too long if they are without hard objects on which to shorten and sharpen those teeth; gnawing on dry bone allows the incisors to be maintained in good condition. In addition to sharpening the teeth, gnawing on bones may also be a good source of phosphorus (Brain 1981:139). Porcupines will collect bones and other hard objects and drag them back to a sheltered lair; they are known to collect many more bones than they gnaw, resulting in an abundant collection. Actualistic studies also indicate that bones from porcupine lairs are not highly fragmented, and they are not skewed in favor of any particular species; they instead reflect the natural abundance of species within the area (Brain 1981:114). What is interesting in the Dadong sample is not their presence, but the relative rarity of gnawing damage. Rodent gnawing is most common in Group 3, but even in this level it is visible on very few elements. In African contexts, Brain (1981) argues that porcupine gnawing on bones in areas where sources of defatted bone is abundant can range as low as 20 percent of a porcupine-generated collection, while in areas of bone scarcity, up to 100 percent of the collection may be gnawed. A 60-70-percent gnawed sample is considered a normal amount of damage on bones from a porcupine lair. At Dadong, the activities of porcupines are evident, but the frequencies by level are very low. It may be that porcupine use of the cave was ephemeral, and the remaining gnawed bones are samples from episodes when porcupines had lairs inside the cave.

\section{Carnivores}

In addition to porcupines, both small and large carnivores can generate impressive accumulations of bone, often in cave contexts (Brain 1981; Kruuk 1972; Schaller 
1967; Stiner 1994; Sutcliffe 1970). Carnivores found at Dadong include small and large cats, civet, hyena, bear, wolf, weasel, and fox (Table 1). Of the taxa present at Dadong, some generate bone accumulations and some very likely do not. The hyena is perhaps the most energetic bone-collecting species among the Dadong carnivores. Hyenas often make use of caves for extensive periods of time as den sites in which to rear their young. Extensive concentrations of bone can build up, often fairly close to a cave entrance or in the daylight zone just outside the entrance (Brain 1981; Kruuk 1972). These animals are capable of bringing down large prey, including young elephants, which they can then dismember in order to drag or carry heavy portions back to a lair. Hyenas also have strong teeth and jaws rendering them capable of chewing, breaking, and consuming large quantities of prey bone (Sutcliffe 1970). Hyena-generated bone fragments often show extensive surface etching from strong digestive compounds.

Wolves also will commonly use caves as lairs for rearing young, and they are known to generate collections of bone (Binford 1981; Stiner 1994). Studies on extant populations indicate that wolves tend to inhabit den sites for shorter periods of time than hyenas (Stiner 1994).

The tiger (Panthera tigris) is a dedicated carnivore capable of subduing prey animals of very large size (Schaller 1967). Tigers are solitary animals that do not maintain groups as the social carnivores do, although tigers also display a degree of social tolerance and are occasionally observed in pairs. Tigers make use of rock shelters and caves either as protected areas in which to rear young or as quiet areas in which a kill can be dragged for feeding (Allen 1940; Schaller 1967; Tate 1947). Modern populations of Chinese tiger subsist primarily on wild pig, but this may reflect the current state of habitat diversity within relict tiger range, rather than an actual preference for wild pig (Allen 1940; MacKinnon and MacKinnon 1974; Tate 1947).

Bears also commonly use cave sites for hibernation, but they tend not to generate large accumulations of bone at hibernation sites. They do not bring food back to a hibernation site-perhaps to avoid attracting the attention of other predators while the animal is in a state of hibernation and, therefore, vulnerable to attack (Stiner 1994). The Chinese black bear (Ursus thibetanus) is essentially a vegetarian bear, subsisting in large part on acorns, honey, fruits, and nuts in addition to any scavenged or hunted prey (Allen 1940; MacKinnon and MacKinnon 1974; Tate 1947).

Carnivore bone processing does not always result in clear evidence of gnaw marks and other forms of carnivore damage on bones, but the presence of gnaw marks does indicate that carnivores were indeed a part of the depositional sequence at Dadong. Less than 3 percent of the Group 3 bone sample has evidence of carnivore damage, and other groups show even lower frequencies (Table 9). Group 2 is similar to Group 3, but all groups show very low levels of carnivore bone processing. The slightly higher frequency of carnivore damage in Group 3 corresponds to the largest sample of large carnivore elements also in Group 3 (Table 3). As discussed above, though present at the site large and small carnivores do not constitute a large component of the total suite. This is surprising given that Dadong Cave is a large space with several side chambers that would have made it a very attractive den site for carnivores such as the hyena.

It has been noted from actualistic studies that carnivore remains form a signifi- 
cant percentage of elements found in carnivore den assemblages (e.g., Brain 1981; Lyman 1994). Klein and Cruz-Uribe (1984:82) argue that in hyena-generated assemblages carnivores constitute at least 20 percent of the carnivore+ungulate portion of the assemblage, and that in archaeological samples carnivores constitute less than 10 to 13 percent of carnivore+ungulate elements, whether measured by NISP or MNI. At Dadong, carnivore elements constitute only 7 percent of the Group 1 sample, and smaller frequencies are observed in Groups 2 and 3 (Table 10). That carnivores constitute a significant percentage of carnivore-generated assemblages is due at least in part to the observation that carnivores that use dens often die there and so become incorporated as elements of the fauna. Carnivore mortality at den sites has several causes, including the stress of winter hibernation on a poorly nourished animal and predation by other species of carnivore (Klein and Cruz-Uribe 1984; Stiner 1994). At Dadong, however, we do not find either the elements of carnivores or bone modification by carnivores in sufficient number to argue that the assemblage was accumulated primarily by carnivores. Other evidence of carnivore activity as well, such as the presence of coprolites, has not been recovered from the deposits. It is possible that accumulations of bone from carnivore den activities may exist in deeper, as yet unexcavated, reaches of the cave.

Another way of evaluating the contribution of carnivores within the assemblage is to look at the ratio of carnivore to ungulate remains. Table 10 includes data on Groups 1 through 3 from Dadong, as well as stratified data from a site identified as a fossil spotted hyena den from Stiner's (1994) study of Neanderthal ecology in the Mousterian of Italy. Data from Brain's (1981) study of brown hyena den assemblages are also included. Although these materials are derived from widely distinct environmental regions outside of East Asia, it is assumed that, although prey type might change dramatically between regions, the overall strategy should be relatively stable. Table 10 indicates that carnivore to ungulate ratios at Dadong are consistently low in comparison to carnivore to ungulate ratios from hyena dens. The aim here is not to argue that the Dadong assemblage was not affected by the feeding and den use activities of large carnivores. Rather, we argue that the sample does not appear to represent a continuous sequence of carnivoregenerated den assemblages.

Carnivores do not confine themselves only to large-bodied prey, nor are carnivores themselves all of large size. Smaller carnivores and predatory birds such as owls and eagles constitute some of the predators that prey on rodents, insectivores, and other taxa. At Dadong these include the civet (Viverra), fox (Vulpes), weasel (Mustela), and tiger cat (Felis). Small-bodied carnivores also regularly use caves as sheltered den sites. Species such as fox and tiger cat bring food back to dens where accumulations of bones can develop (MacKinnon and MacKinnon 1974; Stiner 1994). In addition, owls and other predatory birds commonly use caves. Roosting and nesting owls are known to contribute to bone accumulations through feeding activities, and through the generation of regurgitated owl pellets that contain abundant microvertebrate remains (Andrews 1990; Brain 1981). The dropped owl pellets can become incorporated into cave sediments as dense concentrations of elements. In feeding studies, although dietary preferences may sometimes be seen, owls are found to be opportunistic feeders that will take whatever prey can be had (Andrews 1990; Brain 1981). At Dadong, owls may 
Table io. Carnivore to Ungulate Ratios for Large and Small Carnivores to All Ungulates

VALUES ROUNDED TO THE NEAREST HUNDREDTH

\begin{tabular}{|c|c|c|c|c|c|c|}
\hline & $\begin{array}{l}\text { GROUP I } \\
\text { NISP }\end{array}$ & $\begin{array}{l}\text { GROUP } 2 \\
\text { NISP }\end{array}$ & $\begin{array}{l}\text { GROUP } 3 \\
\text { NISP }\end{array}$ & $\begin{array}{l}\text { GROUP } 4 \\
\text { NISP }\end{array}$ & $\begin{array}{l}\text { ALL } \\
\text { GROUPS } \\
\text { NISP }\end{array}$ & \\
\hline Rhinoceros & 52 & 113 & 168 & 2 & 335 & \\
\hline Large Bovids & 43 & 108 & 57 & 0 & 208 & \\
\hline Stegodon & 35 & 57 & 73 & 3 & 168 & \\
\hline Small Bovids & 14 & 30 & 81 & 3 & 128 & \\
\hline Small Cervids & 7 & 20 & 86 & 0 & 113 & \\
\hline Large Cervids & 15 & 40 & 42 & 1 & 98 & \\
\hline Sus & 2 & 1 & 9 & 0 & 12 & \\
\hline Megatapirus & 5 & 15 & 12 & 1 & 33 & \\
\hline Total Ungulates & 173 & 384 & 528 & 10 & 1095 & \\
\hline Large Carnivores & 6 & 15 & 19 & 0 & 40 & \\
\hline Small Carnivores & 8 & 6 & 4 & 0 & 18 & \\
\hline Total Carnivores & 14 & 21 & 23 & 0 & 58 & \\
\hline $\begin{array}{l}\text { Carnivores/Carnivores plus } \\
\text { Ungulates }\end{array}$ & 0.07 & 0.05 & 0.04 & 0 & 0.05 & \\
\hline Large Carnivores/Ungulates & 0.03 & 0.04 & 0.04 & 0 & 0.04 & \\
\hline Small Carnivores/Ungulates & 0.05 & 0.02 & 0.01 & 0 & 0.02 & \\
\hline Carnivores/Ungulates & 0.08 & 0.05 & 0.04 & 0 & 0.05 & \\
\hline \multicolumn{7}{|l|}{$\begin{array}{l}\text { Brown hyena den assemblages, } \\
\text { Kalahari (calculated from } \\
\text { Brain 1981) }\end{array}$} \\
\hline Carnivores/Ungulates & 0.87 & & & & & \\
\hline $\begin{array}{l}\text { Buca della Iena hyena assemblage, } \\
\text { Italy (Stiner 1994) }\end{array}$ & I1 & I 2 & I3 & I4 & I5 & I6 \\
\hline Large Carnivores/Ungulates & 0.67 & 0.94 & 1.89 & 1.38 & 0.92 & 0.69 \\
\hline Small Carnivores/Ungulates & 0.06 & 0.11 & 0.67 & 0.3 & 0.34 & 0.003 \\
\hline
\end{tabular}

* Additional data from Brain (1981) and Stiner (1994).

have been responsible for the accumulation of small mammal remains. Unfortunately, dense concentrations of microvertebrate elements that might immediately suggest dropped pellets were not evident during the excavation; rather, microvertebrate elements were recovered as dispersed finds. This certainly does not rule out the contributions of owls as an agent of accumulation for the smaller taxa, but identification of dense accumulations that would immediately suggest the remains of owl pellets is not apparent at Dadong. The elements of small taxa that have been recovered, however, are not inconsistent with the elements commonly found in owl pellets. Controlled collection and feeding studies have demonstrated that distal limb bones are either lost or extensively broken, while cranial and axial bone is also lost. Remaining bone accumulations are commonly rich in half mandibles and proximal limb elements, and these elements are found in various states of breakage (Andrews 1990; Brain 1981). At Dadong, insectivore and rodent remains consist of long bones, isolated incisors, and half mandibles. Ribs and vertebrae are either absent or rare (Table 6). Although the sample is small, the pattern at Dadong is consistent with that seen in many cave-roosting predatory birds such as eagles (Andrews 1990; Brain 1981; Lyman 1994). It has also been observed 
that, among species of predatory birds other than owls that produce accumulations of bone, the effects of digestion are often greater than in owl pellets due to the higher acidity of stomach compounds (Andrews 1990; Lyman 1994). However, the Dadong small animal bone does not show extensive corrosion from digestion. All the individual elements show breakage.

Other components of the Dadong fauna may have used the surrounding slopes or cave entrance, and might have become part of the assemblage through natural accumulation. Although the Dadong ungulate assemblage consists primarily of animals that do not tend to inhabit caves, two of the small bovids, the goral (Naemorhedus goral) and the serow (Capricornis sumatraensis), are known to seek shelter in rock crevices and caves for both resting places and for defense (Allen 1940; Schaller 1977; Tate 1947). While the Dadong cave is very likely too large to be preferred by these animals, it is possible that their presence in the cave does not imply the actions of a carnivore.

\section{Hominids}

Hominid bone modification includes cutmarks, percussive damage, and clear evidence of burned bone (Table 9). Morphologically, cutmarks in the sample are short, deep gashes such as would be caused by a tool with a fairly ragged edge (e.g., Potts and Shipman 1981; Shipman and Rose 1983). We do not see, in Dadong or in other East Asian Paleolithic sites, patterning of long cuts that would suggest filleting or cuts made with a high-quality edge (Bakken 1994, 1997). Percussive damage is in the form of pronounced impact scars, close to epiphyseal areas, that are shallower than those seen from carnivore puncture wounds but also the result of impact to green bone rather than dry bone. Very few of these $(n=4)$ are recognized as hominid-caused bone modification in the sample. Although human agency is difficult to determine when looking at evidence for burning (see Lyman 1994 for discussion), it is treated here as evidence of hominid bone modification. Examples of hominid bone modification are rare at Dadong, even though stone tools are found throughout the deposits. The highest frequency of cutmarks on bone is less than 0.5 percent, and it occurs in Group 3, followed by less frequent occurrences in Group 1 and Group 2. If evidence of burning is included in hominid bone modification, then the highest frequency is 5.32 percent in Group 1; of this number, burning is most common and alone contributes 5.13 percent (Table 9). The presence of the highest percentage of burned bone in Group 1 occurs in association with the highest number of stone tools and corresponds to the most diversified use of raw material (Miller-Antonio et al. this volume). Although the modified bone sample size is small, these data in conjunction with the lithic analyses suggest that evidence for hominid activity increases in Group 1 at Dadong.

\section{CONCLUSIONS}

The site of Panxian Dadong records the presence of a suite of taxa in association with a large sample of stone tools and a small sample of hominid remains in deposits that formed during the Middle Pleistocene. Of the four temporal groupings of the fauna discussed here, Group 1 samples a period of climatic transition mov- 
ing into Oxygen Isotope Stage (OIS) 5, while Group 2 correlates with OIS 6, a cool and dry period. Group 3 correlates with OIS 7, a warmer and wetter period, while Group 4 documents a transitional period below the dates for OIS 7 (Rink et al. 2003; Shackleton and Opdyke 1977). Although species representation might be expected to vary substantially among these groups, the taxa that are recorded in abundance have broad tolerance ranges and persist in Middle Pleistocene-aged sites in South China, throughout periods of climatic fluctuation (Xue and Zhang 1991). In addition, South China was not as dramatically impacted by shifts in climate as was North China during this period (Han and Xu 1989; Qi 1989; Wang 1984; Xu 1984).

Measures of taxonomic abundance at Dadong illustrate differing rank orders of abundance between the temporal groups. Large robust taxa such as the rhinoceros and the large bovids and cervids are well represented across time, with highest concentrations seen in Groups 2 and 3. Smaller taxa are represented by fewer elements, as are the large carnivores. There is little difference between the groups in taxonomic representation, levels of carnivore, rodent, and hominid damage, or indicators of bone preservation. The greater percentage of hominid bone modification in Group 1, though interesting in light of the changes in lithic raw material choice discussed by Miller-Antonio (this volume), may yet be an artifact of small sample size; further excavations may clarify this relationship. Element representation does differ substantially between Groups 1 and 2, where cranial elements predominate, and Group 3 in which postcranial elements predominate. Larger, more robust taxa such as the rhinoceros and Stegodon are represented by a greater diversity of elements, though still in quite fragmentary condition.

Agents of accumulation for the Dadong sample include porcupines, owls and other predatory birds, carnivores, hominids, and a few cave-dwelling or caveusing taxa. It is important to remember that the majority of taxa found at Dadong, such as the rhinoceros, Stegodon, cervids, large bovids, and Megatapirus, are not habitual cave dwellers. Their presence in the Dadong sample implies an active agent of accumulation. Each of the possible agents discussed has likely played a role in the formation of these deposits. While the contribution of owls and predatory birds is difficult to quantify, it is highly likely that those species played a role in the accumulation of the rodent and insectivore fraction of the sample. Direct evidence of the bone-processing activities of rodents and carnivores is present in the assemblage, and it documents their use of the cave. Even though the carnivore to ungulate ratios suggest the deposits were not primarily collected by carnivores, the presence of gnaw marks and carnivore elements indicates their presence at least on an occasional basis. It is likely that the sediments are layered accumulations that document periodic use of the cave alternating among carnivores, hominids, and porcupines. Given the time depth represented by the site deposits, as well as the demonstrable use of the cave by hominids, carnivores, and bonecollecting rodents, it is evident that Dadong had a mixed community of occupants during the Middle Pleistocene, probably using the site sequentially rather than at the same time, although that is by no means certain, given that porcupines are known to be tolerated by hyenas and will coexist within the same den site (Brain 1981).

In addition, we do not see the kinds of taphonomic damage that would indicate fluvial transport into the cave and, therefore, we have argued that flooding 
and water transport were not the predominant component of the accumulation process for the fauna (Schepartz et al. in press; Schepartz et al. 2003). Percolating water has also affected the sample, but not to any dramatic extent. This conclusion is based on the condition of the recovered elements and is also supported by geological work, which indicates that tectonic activity, combined with erosion and downcutting, had elevated the cave above the rivers running through the valley by the time that major sediment infilling, and thus the deposition of bone, was taking place (Xiong and Liu 1997; Xiong et al. 1997).

This study, which highlights only some of the complexities of the Dadong faunal assemblage, illustrates that there is still much to be learned from structured faunal comparisons, incorporating studies with measures of taxonomic abundance, from sites in East Asia. Though we have an abundant paleontological record, many taxa, especially those from the subtropical zones, are poorly known or poorly documented. Large cave sites are one promising avenue for documenting Pleistocene environments in South China, as they more commonly contain fossilbearing deposits that contribute to our understanding of hominid occupation of the Old World tropics and subtropics during the Middle Pleistocene.

\section{ACKNOWLEDGMENTS}

This research was supported in part by grants and support from The Field Museum of Natural History, the Henry Luce Foundation, and the National Science Foundation. We thank our colleagues in the Panxian Dadong Collaborative Project for their outstanding contributions to our collaboration and three anonymous reviewers for their constructive comments on the manuscript.

\section{REFERENCES CITED}

Allen, G. M.

1940 The mammals of China and Mongolia. Natural History of Central Asia $11: 2$.

ANDrews, P.

1990 Owls, Caves and Fossils. Chicago: University of Chicago Press.

BAKKEN, DEBORAH

1994 Taphonomic and Faunal Parameters of Pleistocene Hominid Site Assemblages in China. Ph.D. diss. University of Illinois at Urbana-Champaign.

1997 Taphonomic parameters of Middle Pleistocene sites in China. Bulletin of the Indo-Pacific Prehistory Association 16:13-26.

BINFORD, LEwIS R.

1981 Bones, Ancient Men and Modern Myths. New York: Academic Press.

BINFORD, L. R., AND C. K. Ho

1985 Taphonomy at a distance: Zhoukoudian, "the cave home of Beijing man"? Current Anthropology 26(4): 413-442.

Binford, L. R., AND N. M. Stone

1986 Zhoukoudian: A closer look. Current Anthropology 27(5):453-475.

BLACK, DAVIDSON

1931 Evidences of the use of fire by Sinanthropus. Bulletin of the Geological Society of China 11(2): 107-108.

Black, D., P. Teilhard de Chardin, C. C. Young, and W. C. Pei

1933 Fossil man in China: The Zhoukoudian cave deposits with a synopsis of our present knowledge of the late Cenozoic in China. Memoirs of the Geological Survey of China Series A, No. 11. 
Boaz, Noel T., Russell L. Ciochon, Xu Qinqi, And Liu Jinyi

2000 Large mammalian carnivores as a taphonomic factor in the bone accumulation at Zhoukoudian. Acta Anthropologica Sinica, Supplement to Volume 19:224-234.

BraIN, C. K.

1981 The Hunters or the Hunted? An Introduction to African Cave Taphonomy. Chicago: University of Chicago Press.

Breuil, $\mathrm{H}$.

1939 Bone and antler industry of the Choukoutien Sinanthropus site. Paleontologia Sinica New Series D, No. 6, Whole Series No. 117.

Dong Wei, Jin Changzhu, Xu Qingi, Liu Jinyi, Tong Haowen, and Zheng Longting

2000 A comparative analysis on the mammalian faunas associated with Homo erectus in China. Acta Anthropologica Sinica, Supplement to Volume 19:246-256.

\section{Dong ZHUAN}

1996 Looking into Peking Man's Existence: A Taphonomic Analysis of the Middle Pleistocene Homo erectus Site in China. Ph.D. diss. Indiana University, Bloomington.

Grayson, Donald K.

1984 Quantitative Zooarchaeology: Topics in the Analysis of Archaeological Materials. New York: Academic Press.

\section{Han Defen and Xu Chunhua}

1985 Pleistocene Mammalian faunas of China, in Paleoanthropology and Paleolithic Archaeology in the People's Republic of China: 267-286, ed. Wu Rukang and John W. Olsen. New York: Academic Press.

1989 Quaternary mammalian faunas and environment of fossil humans in south China [in Chinese], in Early Humankind in China: 338-391, ed. Wu Rukang, Wu Xinzhi, and Zhang Senshui. Beijing: Science Press.

HuANG W. P., AND Q. R. FANG

1991 Wushan Hominid Site [in Chinese]. Beijing: Ocean Press.

Huang Weiwen, Hou Yamei, and Si Xinqiang

1997 Stone industry from Panxian Dadong, a cave-site of southeastern China [in Chinese with English abstract]. Acta Anthropologica Sinica 16(3):171-192.

JIA LANPO

1980 Early Man in China. Beijing: Foreign Languages Press.

Jia Lanpo and Huang WeIwen

1985 On the recognition of China's Palaeolithic cultural traditions, in Paleoanthropology and Paleolithic Archaeology in the People's Republic of China: 259-266, ed. Wu Rukang and John W. Olsen. New York: Academic Press.

Jin Changzhu, Dong Wei, Liu Jinyi, Wei Guanbiao, Xu Qingi, Zhen Jiajian, Zheng LongTING, HAN LIGANG, AND WANG FAZHI

2000 A preliminary study on the Early Pleistocene deposits and the mammalian fauna from the Renzi Cave, Fanchang, Anhui, China [in Chinese with English abstract]. Acta Anthropologica Sinica, Supplement to Volume 19:235-245.

Keates, Susan G.

1997 Analysing modern human origins in China, in Conceptual Issues in Modern Human Origins Reseach: 294-303, ed. G. A. Clark and C. M. Willermet. New York: Aldine de Gruyter.

2001a An examination of culture and evolution of Middle Pleistocene Chinese hominids, in Human Roots: Africa and Asia in the Middle Pleistocene: 159-185, ed. Lawrence Barham and Kate Robson-Brown. Bristol: Western Academic and Specialist Press Limited.

$2001 b$ Perspectives on "Middle Paleolithic" settlement patterns in China, in Settlement Dynamics of the Middle Paleolithic and Middle Stone Age: 153-175, ed. Nicholas J. Conard. Tübingen: Kerns Verlag.

Klein, Richard G., and Kathryn Cruz-Uribe

1984 The Analysis of Animal Bones from Archeological Sites. Chicago: University of Chicago Press.

KRUUK, HANS

1972 The Spotted Hyaena, a Study of Predation and Social Behavior. Chicago: University of Chicago Press. 
Li YANXIAN AND WEN BENHENG

1986 Guanyindong: A lower Paleolithic site at Qianxi County, Guizhou Province [in Chinese]. Beijing: Cultural Relics Publishing House.

LIU Wu AND Si XINQIANG

1997 The human teeth discovered in Dadong, Panxian County, Guizhou Province [in Chinese with English abstract]. Acta Anthropologica Sinica 16(3): 193-200.

LYMAN, R. LEE

1994 Vertebrate Taphonomy. Cambridge: Cambridge University Press.

MacKinnon J., AND K. MacKinnon

1974 Animals of Asia: The Ecology of the Oriental Region. New York: Holt, Rinehart Winston.

Marean, C. W.

1991 Measuring the post-depositional destruction of bone in archaeological assemblages. Journal of Archaeological Science 18:677-694.

Miller-Antonio, S., L. A. Schepartz, Panagiotis Karkanas, Hou Yamei, Huang Weiwen, and D. BEKKEN

2004 Lithic raw material use at the late Middle Pleistocene Site of Panxian Dadong. Asian Perspectives $43(2): 314-332$.

Olsen, John W., and Sari Miller-Antonio

1992 The Paleolithic in southern China. Asian Perspectives 31(2):129-160.

Pan Yuerong and Yuan Chengwu

1997 Pleistocene primates from Panxian Dadong, Guizhou province [in Chinese with English abstract]. Acta Anthropologica Sinica 16(3):201-208.

PEI, W. C.

1934 a Choukoutien excavations. Memoirs of the Geological Survey of China Series B 7.

$1934 b$ On the carnivora of locality 1 in Choukoutien. Paleontologia Sinica, Ser. C, Vol. 8, Fasc. 1.

1938 Les roles des animaux et des causes naturelles dans la cassure des os. Paleontologia Sinica, New Series D, No. 7.

Pei Wenzhong

1957 The zoogeographical divisions of Quaternary mammalian faunas in China. Vertebrata PalAsiatica 1(1):9-24.

PotTs, Rick, AND PAT SHipman

1981 Cutmarks made by stone tools on bones from Olduvai Gorge, Tanzania. Nature 291:577-580.

Qi GuOCHIN

1989 Quaternary mammalian faunas and environment of fossil humans in north China [in Chinese], in Early Humankind in China: 277-337, ed. Wu Rukang, Wu Xinzhi, and Zhang Senshui. Beijing: Science Press.

1991 The Holocene mammalian faunas of China, in Contributions to the XIII INQUA: 55-60, ed. IVPP, Academia Sinica. Beijing: Science and Technology Publishing House.

QiU ZHONGLANG

1985 The Middle Paleolithic of China, in Paleoanthropology and Paleolithic Archaeology in the People's Republic of China: 187-208, ed. Wu Rukang and John W. Olsen. New York: Academic Press.

Rink, W. J., L. Schepartz, S. Miller-Antonio, W. Huang, Y. Hou, D. Bekken, D. Richter, AND H. JONES

2003 Electron Spin Resonance (ESR) Dating of Tooth Enamel at Panxian Dadong Cave, Guizhou, China, in Current Research in Chinese Pleistocene Archaeology: 95-106, ed. C. Shen and S. Keates. Oxford: BAR International Series.

SCHALler, GeORGE B.

1967 The Deer and the Tiger, a Study of Wildlife in India. Chicago: University of Chicago Press.

1977 Mountain Monarchs, Wild Sheep and Goats of the Himalaya. Chicago: University of Chicago Press.

Schepartz, Lynne, D. A. Bekken, S. Miller-Antonio, C. K. Paraso, and P. Karkanas

2003 Faunal approaches to site formation processes at Panxian Dadong, in Current Research in Chinese Pleistocene Archaeology: 70-94, ed. C. Shen and S. Keates. Oxford: BAR International Series. 
Schepartz, L. A., S. Stoutamire, and D. A. Bekken

In Press Stegodon orientalis from Panxian Dadong, a Middle Pleistocene archaeological site in Guizhou, South China: Taphonomy, population structure and evidence for human interactions. Quaternary International.

Shackleton, N. J., and N. D. Opdyke

1977 Oxygen isotope and paleomagnetic evidence for early northern hemisphere glaciation. Nature 270(5637): 216-219.

SHEN GuANJUN

1993 Uranium-series ages of speleothems from Guizhou Paleolithic sites and their paleoclimatic implications, in Evolving Landscapes and Evolving Biotas of East Asia Since the MidTertiary: 275-282, ed. N. Jablonsky. Hong Kong: Centre of Asian Studies, University of Hong Kong Press.

Shen Guanjun, Liu Jun, And Jin Linhong

1997 Preliminary results on U-series dating of Panxian Dadong in S-W China's Guizhou province [in Chinese with English abstract]. Acta Anthropologica Sinica 16(3):1-8.

Shipman P., AND J. J. Rose

1983 Early hominid hunting, butchering, and carcass-processing behaviors: Approaches to the fossil record. Journal of Anthropological Archaeology 2:57-98.

STINeR, MARY C.

1994 Honor Among Thieves: A Zooarchaeological Study of Neandertal Ecology. Princeton: Princeton University Press.

Sutcliffe, A. J.

1970 Spotted hyena: Crusher, gnawer, digester, and collector of bones. Nature 227:11101113.

TAte, G.H.H.

1947 Mammals of Eastern Asia. New York: MacMillan.

Vu The Long, John de Vos, and Russell Ciochon

1996 The fossil mammalian fauna of the Lang Trang Caves, Vietnam, compared with Southeast Asian fossil and recent mammal faunas: The geographical implications. Bulletin of the IndoPacific Prehistory Association 14:101-109.

WANG LINGHONG

1989 Chronology in Chinese Palaeoanthropology [in Chinese], in Early Humankind in China: 392-404, ed. Wu Rukang, Wu Xinzhi, and Zhang Senshui. Beijing: Science Press.

WANG, P. X.

1984 Progress in Late Cenozoic palaeoclimatology of China: A brief review, in The Evolution of the East Asian Environment: 1:165-187, ed. R. O. Whyte. Hong Kong: Centre of Asian Studies, University of Hong Kong Press.

Wang Wei, Liu Jun, Hou Yamei, Si Xinqiang, Huang Weiwen, Lynne A. Schepartz, and Sari Miller-Antonio

2004 Panxian Dadong, South China: Establishing a record of Middle Pleistocene climatic changes. Asian Perspectives 43(2):302-313.

WeIDENREICH, Franz

1934 The Sinanthropus population of Choukoutien (Locality 1) with a preliminary report on new discoveries. Bulletin of the Geological Society of China 14(4):427-461.

Xiong Kangning and Liu Jun

1997 Development and evolution of the Panxian Dadong cave [in Chinese with English abstract]. Acta Anthropologica Sinica 16(3):239-246.

Xiong Kangning, Qin Qiwan, Zhang Hangnang et al.

1997 Morphometry and speleogenesis of Shiliping area, Panxian County [in Chinese with English abstract]. Acta Anthropologica Sinica 16(3):247-253.

Xu Qunhua

1984 Climate during the Hexian Man's time [in Chinese with English abstract]. Acta Anthropologica Sinica 3(4):383-391.

Xue, X. X. and Zhang, Y. X.

1991 Quaternary mammalian fossils and fossil human being, in The Quaternary of China: 307374, ed. Zhang, Z. H. and Shao, S. X. Beijing: China Ocean Press. 
Young, C. C.

1939 New vertebrate horizons in China. Bulletin of the Geological Society of China No. 17.

Zhang Zhenhong, Liu Jun, Zhang Hangang, and Yuan Chengwu

1997 A Pleistocene mammalian fauna from Panxian Dadong, Guizhou Province [in Chinese with English abstract]. Acta Anthropologica Sinica 16(3): 207-220.

\title{
ZHOU MingZHEN
}

1964 Mammals of "Lantian Man" locality at Lantian, Shensi. Vertebrata PalAsiatica 8(3):301311.

\begin{abstract}
The faunal assemblage from the site of Panxian Dadong provides evidence for a general continuity in species representation throughout a period of approximately 120 kya. Taxonomically, faunal material from Dadong includes classic taxa of the Middle Pleistocene Ailuropoda-Stegodon faunal complex of South China. Taxonomic abundance measures document a sample that is rich in large ungulate species including rhinoceros, stegodonts, and large bovids. These data are further examined in light of assemblage formation processes, temporal distribution, and environmental context. Taphonomic data that demonstrate the presence and activities of bonecollecting species (including porcupines, hominids, and large and small carnivores) suggest that Dadong Cave was an attractive shelter that saw many uses during the period analyzed. These include hominid foraging, porcupine bone collecting, and carnivore scavenging and hunting. Keywords: Middle Pleistocene, South China, Ailuropoda-Stegodon fauna, hominid.
\end{abstract}

